\title{
Role Strains and Mood in Husbands of Women with Fibromyalgia Syndrome: A Test of the Stress Process Model
}

\author{
Silvia M. Bigatti' ${ }^{*}$, , Jennifer R. Lydon ${ }^{2}$ and Brittany M. Brothers ${ }^{3}$ \\ ${ }^{I}$ IUPUI, Department of Psychology, 402 North Blackford Street, LD 124, Indianapolis, Indiana, USA \\ ${ }^{2}$ Robert L. Roudebush Veteran's Administration Medical Center, Indianapolis, USA \\ ${ }^{3}$ The Ohio State University, OH, USA
}

\begin{abstract}
Spouses of patients experience role strains as a result of informal caregiving, which has been associated with mood in numerous research studies. However, most research is on female caregivers, and little is known about the experience of male spouses, or of the caregiving provided to fibromyalgia patients. The Stress Process Model was used to examine mediators and moderators of the relation between role strain and mood among 135 husbands of women with fibromyalgia. Results indicated that the more activities of daily living and instrumental activities of daily living performed by the husband, the greater the role strain. Role strain was associated with worse mood. A test of the Stress Process Model supported a partial mediation model, where social support and emotion-focused coping partially mediated the relation between role strain and mood. No evidence was found for a moderation model or for problem-focused coping as a mediator. Our research suggests significant impairment and caregiving needs among this patient population, which in turn relates to the mood of the husband who is also an informal caregiver. Our findings also support the Stress Process Model in explaining the complexity of caregiving effects. The results of the study suggest avenues for intervention for individuals strained by their partners' illness.
\end{abstract}

Spouses of chronically ill individuals have poorer mental health than comparison groups and the general population [1, 2]. Spouses may be affected because the illness may require informal caregiving, including assistance with activities of daily living (ADLs; such as toileting, dressing), instrumental activities of daily living (IADLs; such as shopping), and taking over responsibilities that the patient can no longer perform (such as cleaning, cooking). These caregiving responsibilities may interfere with spouses' abilities to perform other roles, resulting in role strains.

Role strains, experienced daily by most individuals, are defined as the difficulties felt by individuals who have multiple roles with accompanying obligations [3]. For caregivers, the additional responsibility of helping a patient with a health condition may divert much needed resources from the other roles currently fulfilled by the individual, causing role strain. Roles typically examined for strain include work, domestic environment, sexual relations, family relations, and social relations. Of the employed caregiving husbands in a national study of frail elderly, $32 \%$ reported working fewer hours, $28 \%$ indicated they rearranged their schedule, and $24 \%$ took time off without pay because of their wives' illness [4]. In the domestic environment, husbands report an increase in the amount of time spent on household chores as a direct result of their wives' illness or disability [5]. A chronic illness may affect the couple's sexual relations as well. For example, patients with a rheumatic disease listed pain or weakness, fatigue, and lack of interest as the top

*Address correspondence to this author at the IUPUI, Department of Psychology, 402 North Blackford Street, LD 124, Indianapolis, Indiana, USA; Tel: 317-274-6754; Fax: 317-274-6756; E-mail: sbigatti@iupui.edu three problems experienced in their sexual relation [6]. Caregivers also sacrifice activities that bring them personal and social fulfillment, such as vacations or hobbies [7], or contacts with friends and family [8].

Individuals with higher demand loads from their care recipients experience more strain than those with lower caregiving demands. For example, Northouse, Templin, and Mood [9] found that illness severity in breast cancer patients had a direct effect on predicting role adjustment in husbands. In a different study examining colon cancer patients, the presence of a colostomy was predictive of higher levels of role strains in male and female spouses [10]. An increase in the number of ADLs or IADLS performed has also predicted more strain in Alzheimer's [11] and stroke [12] caregivers.

Identifying and understanding caregiving related role strains are important because these have been linked to a variety of negative psychological outcomes. Chang, Brecht, and Carter [13] found that occupying a larger number of roles was correlated with more hostility and anxiety. Research has tied caregiving to depression $[5,14]$ and anxiety [12], suggesting the need to better understand and prevent these strains to improve outcome for caregivers and their care recipients.

The present study was guided by Pearlin's Stress Process Model [15], and focused on three of its components: stressors, resources, and outcomes. Stressors are problems or negative events that threaten a person's ability to adapt and include eventful (single-event) or chronic stressors. Among the four types of chronic stressors illustrated by Pearlin are role strains, which was the focus of the present study. Resources are of a social or personal nature, used to mediate the effects of the stressor and include coping skills and social 


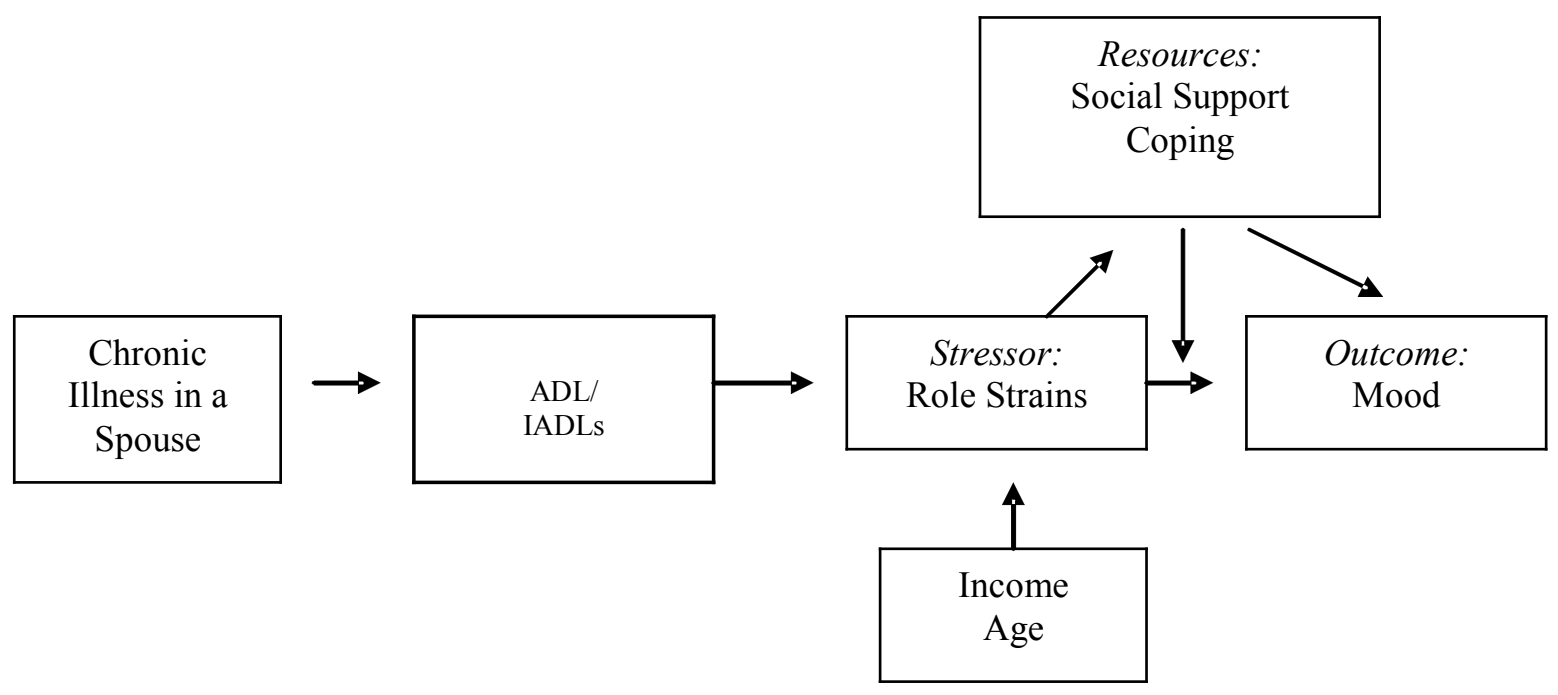

Fig. (1). Stress Process Model (Adapted from [49] Pearlin, Turner, \& Semple, 1989, p. 207).

support. Outcomes are the results of the influence of the stressors after taking into account the effects of the resources. Outcomes can be singular or multiple and are varied depending on the stressor. In the present study, we have operationally defined stressors as role strains, available resources as social support and coping, and mood as our outcome of interest (Fig. 1).

In the general literature, social support has been found to function both as a moderator and mediator between stressors and psychological well-being [16]. For example, in caregivers, social support moderates the effects between the patients' level of cognitive dysfunction after a traumatic brain injury and the caregivers' satisfaction with life [17]. Additionally, social support, through the mediating influence of social participation, has been related to higher levels of wellbeing and life satisfaction in informal caregivers of the elderly [8]. Furthermore, Chang and colleagues [13] have reported that in those caring for Alzheimer's and other dementia patients, occupying more roles was related to less social support, which was related to more depression and less satisfaction. Some research suggests that male spousal caregivers report experiencing lower levels of social support than women spousal caregivers [18]. Clearly social support plays an important role for adjustment in caregivers and men who receive lower social support may be at risk for worse mental health outcomes.

Coping has traditionally been examined in terms of emotion and problem focused coping [19]. Emotion-focused coping clearly has been identified as a mediator in caregivers. For example, in caregivers of the cognitively impaired, emotional avoidance coping mediates the relation between role strain and depressive symptoms [20]. Specifically, Patterson et al. [20] used the Stress Process Model to analyze the relation between patient's functioning, the stressor of role strain, the resources of coping and social support, and the outcome of depressive symptoms. The patient's functioning, as defined by clinical dementia rating and behavior problems, directly predicted role strain. As predicted by the Stress Process Model, role strain, mediated by the use of emotional avoidance coping, predicted depressive symptoms. Research has also supported problem focused coping as a potential mediator. For example, in a study using a modified version of the Stress Process Model, Goode, Haley, Roth and Ford [21] found that increases of approach coping led to decreases in depression.

Fibromyalgia Syndrome (FMS) is a chronic condition well suited to study role strains among husbands. FMS is a chronic, non-fatal pain syndrome classified as a rheumatic disorder that primarily affects women. Patients typically report long-term and widespread pain and stiffness both in the morning and after periods of extended inactivity [22]. FMS is also associated with depression and sleep problems which may exacerbate fatigue, another common symptom [23]. Husbands of FMS patients have reported worse affective states, lower health and higher depression than a comparison group of men with healthy wives [24]. Although there is an understanding in the literature regarding the debilitating nature of this disease, it is yet unclear the extent to which husband caregivers of FMS patients assist their wives with activities of daily living, and beyond this rather objective measure, the degree to which their assistance relates to increased role strain.

The primary purpose of the present study was to examine caregiving responsibilities and role strain in husbands of women with fibromyalgia and to better understand how social support and coping might influence the relations between role strain and mood. Thus, there were five primary aims. The first three aims were to understand caregiver responsibilities and role strains in these husbands of patients with FMS. Specifically, the first two aims were to examine the extent to which husbands of women with fibromyalgia (1) helped their wives with ADLS and IADLS and (2) experienced the stressor of role strain. Aim (3) was to understand the degree to which these two variables were related. The fourth and fifth aims placed the role strain within a theoretical framework examining (4) the degree to which greater role strain was associated with lower mood and (5) how psychosocial resources, namely social support and coping might moderate or mediate the relation between role strain and mood (Fig. 1). 


\section{METHODS}

\section{Participants}

The average participant was an older $(m=59, \mathrm{SD}=11)$, Caucasian $(90 \%)$, at least partially college-educated individual $(89 \%)$ who had been married over 25 years $(\mathrm{SD}=15)$ with an above average income $(m=\mathrm{US} \$ 50,000, \mathrm{SD}=$ US\$20,000). Most husbands were either employed full time $(47.5 \%)$ or retired $(36.7 \%)$.

The FMS patients themselves reported significant physical disability and psychological distress [25]. Specifically, they scored lower on quality of well-being, a measure of physical and mental health, than women in the general population and even women with Osteoarthritis. Only $8.9 \%$ of the patients, however, had total work-related disability because of the FMS, 5.2\% had partial disability, $11.1 \%$ had reduced their work hours because of the FMS without the benefit of workrelated disability, and $18.5 \%$ continued to work full time. The rest did not work for reasons unrelated to the syndrome.

\section{Measures}

Project Questionnaire. In order to gather demographic information, a project questionnaire was developed for this study. Items included ethnicity, education level, employment status, and annual household income. Information regarding the patients' disability, specifically work status, was also collected.

\section{Caregiving Responsibilities}

ADLs and IADLs - Illness Impact Form. Originally designed by Gallo and reported in Sexton [26], this scale measures the amount of assistance provided by the spouse in five ADLs and five IADLs because of the fibromyalgia; with responses ranging from never $=0$ to always $=3$ for each item. This scale can yield a total score as well as subscale scores for ADLs and IADLs. Higher scores indicate more caregiving needs by the patient. Internal consistency for the present study was $\alpha=.83$ for the total score.

\section{Stressors}

Role Strains - Psychological Adjustment to Illness ScaleSpouse Self-Report (PAIS). The PAIS was created in order to assess how a spouse's illness is affecting various roles inherent in a person's everyday life [27]. It contains 46 items with 7 subscales of which 5, used in the present study, measure role strains in vocational environment, domestic environment, sexual relations, extended family relations, and social environment. Specifically, questions ask whether the "spouse's illness has interfered with" their ability to carry out various activities/roles. Responses are on a 4-point scale of distress [27], with higher ratings indicating poorer adjustment. Internal consistency reliability coefficients range from a high of .87 for domestic environment to a low of .66 for extended family [27]. The measure correlates highly with other measures of psychological adjustment to illness, such as the Global Adjustment to Illness Scale $(r=.81)$. Internal consistency for the present study was $\alpha=.78$ for the total score.

\section{Resources}

Social Support - Interpersonal Support Evaluation List. This measure was specifically designed to assess the "role social supports play in protecting people from the pathogenic effects of stress" (p.74) [28]. It consists of a list of 40 true/false statements that assess the availability of various sources of support. Higher scores reflect more social support. Validity was tested with other social support measures $(\mathrm{r}=.46$ to $r=.62)$, self-esteem measures $(r=.74)$, and self-disclosure measures $(\mathrm{r}=.40)$. The authors reported good six month testretest reliability $(\mathrm{r}=.74)$. Internal consistency for the present study was $\alpha=.79$.

Coping- Ways of Coping Questionnaire. Coping strategies were measured using the Ways of Coping Questionnaire [29]. The measure has 66 items that can be divided into two scales: problem- and emotion-focused coping. Higher scores reflect more use of that style. The measure has internal consistency reliabilities ranging from $\alpha=.61$ to $\alpha=.79$. Construct validity has been supported by consistency with theoretical predictions [30]. Reliability was estimated for the present study, internal consistency of these two subscales were $\alpha=.81$ for emotionfocused coping and $\alpha=.85$ for problem-focused coping.

\section{Outcome}

Mood - Profile of Mood States (POMS) short form. The POMS short form [31] is designed to measure mood disturbance in individuals by having them respond to the 30 adjectives listed on a five point Likert scale $(0=$ not at all to $4=$ extremely). A total mood disturbance score can be calculated, with higher scores indicating more mood disturbance. This instrument has good concurrent validity, and low to moderate correlations with measures of social desirability. Internal consistency for the present study was $\alpha=.87$.

\section{Procedure}

Participants were recruited from a larger study of patients with fibromyalgia recruited through mass mailing to members from a Southern California Health Maintenance Organization. The purpose of the original study was to examine the effects of experimentally manipulated social support and education on the health status and health care use of people with FMS. To protect confidentiality, the FMS women who reported being married or in stable, live-in relations were sent letters asking them to refer their spouse to the present study. A total of 600 participants were recruited for the larger study, of these, 574 (95\%) were women and of these, $384(67 \%)$ reported that they were either married or in a stable relationship. Recruitment letters were sent to these 384 participants asking them to refer their husbands to the present study. A total of 135 male spouses $(35 \%$ of those eligible) volunteered. No differences were found between the wives of husbands who volunteered for the present study and those whose husbands did not volunteer on any physical health or psychosocial variables $(p>.05)$ [24]. Wives of non-volunteers were more likely to have dropped out of the larger study than wives of volunteers [24].

Husbands of women without a chronic or acute illness were recruited as a comparison group, but not used in the present analyses. Husbands who volunteered were interviewed in the research offices. Interviews lasted approximately 1.5 hours. After receiving an overview of the study and signing an informed consent form, they completed a battery of instruments and were compensated $\$ 50.00$ for their participation. 
Table 1. Zero Order Correlations, Means and Standard Deviations, and Actual and Possible Ranges for All Variables in Study

\begin{tabular}{|c|c|c|c|c|c|c|c|c|c|c|c|c|c|c|c|}
\hline Variable & 1 & 2 & 3 & 4 & 5 & 6 & 7 & 8 & 9 & 10 & 11 & 12 & 13 & 14 & 15 \\
\hline 1. Age & $\bullet$ & & & & & & & & & & & & & & \\
\hline 2. Education ${ }^{1}$ & .08 & - & & & & & & & & & & & & & \\
\hline 3. Income $^{2}$ & -.23 & .29 & $\bullet$ & & & & & & & & & & & & \\
\hline 4. Activities of daily living & -.03 & -.14 & -.16 & $\bullet$ & & & & & & & & & & & \\
\hline 5. Instrumental ADLs & -.09 & .05 & -.12 & .64 & • & & & & & & & & & & \\
\hline 6. Sexual role strain & .13 & -.10 & -.20 & .22 & .29 & - & & & & & & & & & \\
\hline 7. Family role strain & -.13 & -.13 & -.16 & .40 & .42 & .39 & • & & & & & & & & \\
\hline 8. Social role strain & -.12 & -.13 & -.07 & .43 & .49 & .43 & .47 & - & & & & & & & \\
\hline 9. Domestic role strain & -.11 & -.15 & -.28 & .41 & .49 & .41 & .67 & .57 & $\bullet$ & & & & & & \\
\hline 10. Vocational role strain & .24 & -.11 & -.32 & .36 & .34 & .30 & .31 & .36 & .40 & $\bullet$ & & & & & \\
\hline 11. PAIS total & -.03 & -.16 & -.26 & .48 & .55 & .71 & .74 & .81 & .84 & .57 & $\bullet$ & & & & \\
\hline 12. Social support & .16 & .15 & .06 & -.32 & -.28 & -.41 & -.39 & -.45 & -.44 & -.08 & -.51 & $\bullet$ & & & \\
\hline 13. Problem-focused coping & -.05 & .22 & .16 & -.12 & .00 & -.10 & .03 & -.12 & -.06 & -.17 & -.11 & .25 & $\bullet$ & & \\
\hline 14. Emotion-focused coping & -.13 & -.04 & -.09 & .14 & .16 & .23 & .31 & .30 & .29 & .12 & .35 & -.13 & .45 & - & \\
\hline 15. Mood & -.34 & -.12 & -.08 & .21 & .25 & .10 & .26 & .43 & .41 & .28 & .41 & -.36 & -.14 & .39 & $\bullet$ \\
\hline Mean & 58.73 & 3.6 & 5.6 & 1.02 & 2.93 & 5.70 & 1.84 & 4.82 & 4.10 & 2.50 & 18.86 & 32.22 & 1.30 & 4.57 & 9.10 \\
\hline Standard Deviation & 0.95 & 1 & 2 & 0.13 & 0.24 & 3.74 & 2.44 & 4.13 & 3.72 & 2.03 & 12.06 & 6.87 & .55 & 1.44 & 16.60 \\
\hline Actual Range & $27-85$ & 1 to 5 & 1 to 8 & $0-6$ & $0-13$ & $0-17$ & $0-12$ & $0-18$ & $0-14$ & $0-9$ & $1-50$ & $11-40$ & $0.75-9.25$ & $0.86-8.33$ & -19 to 67 \\
\hline Possible Range & $21-100$ & 1 to 5 & 1 to 8 & $0-15$ & $0-15$ & $0-18$ & $0-15$ & $0-18$ & $0-24$ & $0-18$ & $0-93$ & $0-40$ & $0-48$ & $0-84$ & -25 to 100 \\
\hline
\end{tabular}

Correlations at or above .17 are significant at $\mathrm{p}<.05$ - Correlations at or above .22 are significant at $\mathrm{p}<.01-$ Correlations at or above .30 are significant at $\mathrm{p}<.001$ Two-tailed

${ }^{1}$ Education: 1 = high school, $2=$ some college, 3 = bachelor's degree, $4=$ master's degree, $5=$ doctorate.

${ }^{2}$ Income: $1=<\$ 10,0002=\$ 10,000-\$ 20,000,3=\$ 20,001-\$ 30,000,4=\$ 30,001$ to $\$ 40,000,5=\$ 40,001$ to $\$ 50,000,6=\$ 50,001$ to $\$ 60,0007=\$ 60,001$ to $\$ 70,0008=>$ $\$ 70,000$.

\section{RESULTS}

\section{Correlations Among Study Variables}

Pearson product moment correlations examined the relations between the various role strains and the other variables in the study. Total role strains (PAIS total score) correlated with all variables except for age, education, and problemfocused coping (Table 1). Higher total strain was associated with lower income, more help with ADLs and IADLs, lower social support, more use of emotion focused coping, and worse mood. Because of the finding that income was significantly related to role strain, it was controlled for in all of the regression analyses.

\section{Aim 1: Caregiving Responsibilities of Husbands}

Husbands were asked how often they assisted their wives in activities of daily living (ADLs) and instrumental activities of daily living (IADLs) because of the fibromyalgia. Findings suggest that husbands of women with fibromyalgia do indeed engage in caregiving, helping wives with both ADLs and IADLs, as can be seen in Table 2. Within the sample, $48 \%$ of the husbands reported helping their wives with at least one ADL, and $77 \%$ of the husbands indicated that they helped their wife with at least one IADL specifically because of the limitations imposed by the FMS.

\section{Aim 2: Role Strains in Husbands}

Means and standard deviations were examined for the entire group $(n=135)$ to determine their reported level of role strain. Husbands reported varied role strain (total score mean $=18.86, \mathrm{SD}=12.06$, range $=1$ to 50 out of a possible 0 to 93 ) with highest role strains in sexual roles and the lowest in extended family relations (Table $\mathbf{3}$ ).

\section{Aim 3: Relation Between Role Strain and Caregiving Responsibilities}

A hierarchical multiple regression analysis was conducted, controlling for income, to examine the relation between IADLs, ADLs and total role strain. Results indicated that even after controlling for income, both IADLs and ADLs were associated with increased role strain, $\mathrm{R}^{2} \Delta=.30$, $\mathrm{F} \Delta(3,131)=30.32, \mathrm{p}<.001$, although the relation was stronger for IADLs (Table 4).

\section{Aim 4: Relation Between Role Strains and Mood}

The correlation analysis showed that total role strain was moderately related to $\operatorname{mood}(\mathrm{r}=.41, \mathrm{p}<.01)$ as assessed by the POMS (Table 1). When examining the five subscales of the PAIS included in this study, all but sexual role strain was significantly related to lower mood, with social role strains showing the strongest relation. 
Table 2. Caregiving Responsibilities of Husbands (Aim 1)

\begin{tabular}{|c|c|c|c|}
\hline Activities of Daily Living (ADLs) & $\%$ & Instrumental Activities of Daily Living (IADLs) & $\%$ \\
\hline Dressing & & Trips outside & \\
\hline Never & 63.7 & Never & 58.5 \\
\hline Sometimes & 35.6 & Sometimes & 30.4 \\
\hline Most times & 0.7 & Most times & 8.1 \\
\hline Always & 0 & Always & 3.0 \\
\hline Eating & & Organizing appointments & \\
\hline Never & 83 & Never & 66.7 \\
\hline Sometimes & 13.3 & Sometimes & 27.4 \\
\hline Most times & 3.0 & Most times & 4.4 \\
\hline Always & 0.7 & Always & 1.5 \\
\hline Bathing & & Managing finances & \\
\hline Never & 87.4 & Never & 54.1 \\
\hline Sometimes & 11.1 & Sometimes & 24.4 \\
\hline Most times & 0.7 & Most times & 13.3 \\
\hline Always & 0.7 & Always & 8.1 \\
\hline Use the Toilet & & Taking medication & \\
\hline Never & 93.3 & Never & 72.6 \\
\hline Sometimes & 6.7 & Sometimes & 23.7 \\
\hline Most times & 0 & Most times & 2.2 \\
\hline Always & 0 & Always & 1.5 \\
\hline Walk in house & & Shopping & \\
\hline Never & 80.7 & Never & 37 \\
\hline Sometimes & 17.0 & Sometimes & 42.2 \\
\hline Most times & 2.2 & Most times & 15.6 \\
\hline Always & 1.5 & Always & 5.2 \\
\hline
\end{tabular}

\section{Aim 5: Moderation and Mediation Analyses \\ Moderation}

As statistically recommended by Frazier, Tix, and Barron [32], the moderation of total role strains and mood by social support and emotion and problem focused coping was conducted by first centering the predictor and moderating variables (i.e. subtracting the mean of each variable to create a version of the variable in which the mean score is zero). Three interaction terms were then created by using the new centered variables (predictor*moderator). In order to control for inflation of Type I error, all three potential moderations were examined in one hierarchical regression. Specifically, the predictor and potential moderating variables were entered into the first step of the regression, and the three interaction terms were entered into the second step. The second step of the regression did not explain additional variance, $\mathrm{R}^{2} \Delta=$ $.037, \mathrm{~F} \Delta(7,127)=2.48, \mathrm{p}=.064$, suggesting that none of the three variables of interest moderated the relation between role strains and mood.

\section{Mediation}

As indicated by Baron and Kenny [33] three regressions may be used to examine the four steps of mediational analyses. In the first and second steps, in separate regressions, a significant relation must be demonstrated between both the predictor and the outcome and between the predictor and the mediator. In the third and fourth steps, a hierarchal linear regression is used to establish a relation between the mediator and the outcome variable and a reduction in the relation between the predictor and outcome variable when controlling for the mediator. Potential mediation analyses were examined using a variation of the Sobel significance test [32].

\section{Social Support and Coping as Mediators}

Social support and emotion focused coping were examined together as potential mediators; problem focused coping was not found to be related to role strains or mood (Table 1) and was excluded from the following analyses. As can be seen in Table 5 when controlling for income, significant relations were present between the predictor and outcome (Path C; Regression 1) (Fig. 2), the predictor and mediators (Path $\mathrm{A}$; Regression 2) and the mediators and the outcome (Path B; Regression 3). Moreover, the strength of the relation between role strain and mood, predictor and outcome respectively $(\beta=.41, \mathrm{p}<.001$, Path $\mathrm{C})$, was reduced $(\beta=.189, \mathrm{p}=$ .049 , Path C) (Fig. 2) when controlling for social support and emotion focused coping, the proposed mediators. Importantly, however, the relation between role strain and well being continued to be significant indicating only partial mediation. Using a variation of Sobel's statistic [32], both social support $(\mathrm{z}=3.571, \mathrm{p}<.001)$ and emotion focused coping $(\mathrm{z}=2.977, \mathrm{p}<.01)$ were independently found to be statistically significant partial mediators. The final regression model with both mediators accounted for $27.4 \%$ of the variance in mood. 
Table 3. Role Strain Subscales Means

\begin{tabular}{|c|c|c|}
\hline Subscales & Means (SD) & Range \\
\hline Vocational Environment & $0.42(0.34)$ & \multirow{6}{*}{$\begin{array}{l}\text { Fo to } 3 \\
\text { For the individual subscales, scores were added and then divided by the number } \\
\text { of items on each scale so that comparisons could be made among subscales. }\end{array}$} \\
\hline $\begin{array}{l}\text { (effects on work, school or home activities) } \\
\text { Domestic Environment }\end{array}$ & $0.51(0.47)$ & \\
\hline (effects on family members) & & \\
\hline $\begin{array}{l}\text { Social Environment } \\
\text { (effects on social and leisure time activities) }\end{array}$ & $0.80(0.69)$ & \\
\hline $\begin{array}{l}\text { Sexual Relations } \\
\text { (effects on quality of sexual functioning) }\end{array}$ & $0.95(0.62)$ & \\
\hline $\begin{array}{l}\text { Extended Family Relations } \\
\text { (effects on extended family members) }\end{array}$ & $0.37(0.49)$ & \\
\hline
\end{tabular}

\section{DISCUSSION}

We examined caregiving responsibilities, role strains and their relation with mood among husbands of women with fibromyalgia. Our sample consisted of older, mostly White, well-educated men. As expected, we found that the number of ADLS and IADLs, which measure caregiving responsibilities, predicted role strain and that role strains were significantly related to mood. Using the Stress Process Model as a guide, we found that the resources of social support and coping partially mediated the relation between role strains and mood, but that neither of these variables moderated the relationship.

Table 4. Summary of Regression Analyses for ADLs and IADLs as Predictors of Total Role Strains (Aim 3)

\begin{tabular}{|l|c|c|c|}
\hline \multicolumn{1}{|c|}{ Variable } & B & SE $\boldsymbol{B}$ & Beta \\
\hline \hline First Step & & & \\
Income & -1.53 & 0.50 & $-0.26^{* *}$ \\
Multiple R & 0.26 & & \\
F-test & $9.39^{* *}$ & & \\
Variance & $6.6 \%$ & & \\
\hline Second Step & & & \\
Income & -1.05 & 0.42 & $-0.18^{*}$ \\
ADLs & 1.54 & 0.72 & $0.20^{*}$ \\
IADLs & 1.73 & 0.39 & $0.40^{* * *}$ \\
Multiple R & 0.60 & & \\
F-test & $24.73 * * *$ & & \\
Variance & $36.15 \%$ & & \\
${ }^{*} \mathrm{p}<.05$, two-tailed, ${ }^{* *} \mathrm{p}<.01$, two-tailed, ${ }^{* * *} \mathrm{p}<.001$, two-tailed.
\end{tabular}

The degree of caregiving of these husbands was noteworthy. For example, over $36 \%$ of husbands reported that they at least sometimes helped their wives dress (an activity of daily living) because of the fibromyalgia symptoms, and $48 \%$ reported helping in at least one ADL. In terms of instrumental activities of daily living, such as trips outside, shopping, or taking medication, these husbands were even more involved, in the realm of $27.4 \%$ for medication to $63 \%$ for shopping, with $77 \%$ of husbands indicating that they helped in at least one IADL. Clearly, although patients with fibromyalgia in general need little help with ADLs, the impact of the condition on IADLs is significant, suggesting that FMS extends beyond the patient to impact spouses and possibly others within the family environment. This is the first published record of caregiving activities by husbands of fibromyalgia patients. These findings shed light on the needs of these patients and on the caregiving provided by their spouses. These findings are important because approximately two to five percent of the population suffer from fibromyalgia, with the syndrome disproportionately affecting women [34-36].

We found varying level of role strain in these husbands. The highest strain was reported in the sexual role, followed by social, domestic, vocational and extended family relations. The only other published data of role strains of spouses obtained suggests that husbands of fibromyalgia patients reported similar or higher role strain than spouses of colon cancer patients [10]. Although the caregiving needs of fibromyalgia patients described in the previous paragraph would suggest elevated role strains, it is surprising that fibromyalgia would be associated with similar or higher role strain than colon cancer, with its associated threat to life and treatment demands. Our findings suggest that we should further examine and understand role strains in spouses of patients with chronic debilitating health conditions such as fibromyalgia. Some specific characteristics of fibromyalgia may explain the high role strains in these subscales. FMS is a chronic, long-term pain condition; therefore, its impact is also long term. Because the pain is debilitating, sexual relations may become difficult [6], household chores are hard to manage, and typical social activities of the couple may be forgotten or strained because of the illness (see review in [37]).

We found a significant relation between role strains and caregiving responsibilities, supporting previous research in caregivers of several disease types (e.g. [12]). Specifically, after controlling for income, husbands' reports of help with ADLs and IADLs accounted for $30 \%$ of the variance in role strains. Role strain, in turn, was moderately related to mood, although interestingly the highest strain, sexual, showed no relation to mood. These findings support previous work linking caregiving strain with worse mood and more moodrelated disorders [12]. We were surprised to find no relation between sexual role strain and mood, a finding that requires 
Table 5. Social Support and Emotion-Focused Coping as Mediators of Role Strain and Mood (Aim 5)

\begin{tabular}{|c|c|c|c|c|c|}
\hline Variable & B & SE $B$ & Beta & $F(d f)$ & $\mathbf{R}^{2}$ \\
\hline \multicolumn{6}{|l|}{$\begin{array}{l}\text { Regression } 1 \text { (Path C): } \\
\text { Dependent: Mood (POMS) }\end{array}$} \\
\hline First Step: Income & -0.636 & 0.710 & -0.077 & $\begin{array}{c}0.801 \\
(1,133)\end{array}$ & 0.006 \\
\hline Second Step: Role Strain & 0.569 & 0.113 & $0.410^{* * *}$ & $\begin{array}{c}13.106^{* * *} \\
(2,132)\end{array}$ & 0.166 \\
\hline \multicolumn{6}{|l|}{$\begin{array}{l}\text { Regression } 2 \text { (Path A): } \\
\text { Dependent: Role Strain (PAIS) }\end{array}$} \\
\hline First Step: Income & -1.534 & 0.500 & $-0.257 * *$ & $\begin{array}{l}9.390 * * \\
(1,133)\end{array}$ & 0.066 \\
\hline Second Step: Income & -1.226 & 0.412 & $-0.205^{* *}$ & $27.048^{* * *}$ & \\
\hline Social Support & -0.814 & 0.122 & $-0.464 * * *$ & $(3,131)$ & 0.382 \\
\hline Emotion Focused & 2.249 & 0.582 & $0.269 * * *$ & & \\
\hline \multicolumn{6}{|l|}{$\begin{array}{l}\text { Regression } 3 \text { (Path B and C'): } \\
\text { Dependent: Mood (POMS) }\end{array}$} \\
\hline First Step: Income & -0.636 & 0.710 & -0.077 & $\begin{array}{c}0.801 \\
(1,133)\end{array}$ & 0.006 \\
\hline Second Step: Income & -0.226 & 0.624 & -0.028 & $14.718^{* * *}$ & \\
\hline Social Support & -0.769 & 0.184 & $-0.318 * * *$ & $(3,131)$ & 0.252 \\
\hline Emotion Focused & 3.975 & 0.881 & $0.345^{* * *}$ & & \\
\hline Third Step: Income & 0.093 & 0.638 & 0.011 & & \\
\hline Social Support & -0.557 & 0.211 & $-0.230 * *$ & $12.280 * * *$ & \\
\hline Emotion Focused & 3.389 & 0.920 & $0.294 * * *$ & $(4,130)$ & 0.274 \\
\hline Role Strain (PAIS) & 0.261 & 0.131 & $0.189 *$ & & \\
\hline
\end{tabular}

$* \mathrm{p}<.05$, two-tailed, $* * \mathrm{p}<.01$, two-tailed, $* * * \mathrm{p}<.001$, two-tailed.

Note. Higher scores on the PAIS indicate more role strain and higher scores on the POMS are indicative of worse mood.

further study and that may be specific to FMS patients and their specific disease characteristics.

An important contribution of the present study is the mediation and moderation analyses we conducted as a test of the Stress Process Model. We conceptualized role strains as the stressor. Resources for the present study were social support and coping, and they were tested as both moderators and mediators of the relation between role strains and mood. Both social support and emotion-focused coping mediated the relation between role strains and emotional-well being. However, we found no support for a moderation of these two resources, or for a mediation of problem-focused coping.

Social support networks may change with the advent of a chronic illness because the illness limits the number and quality of activities. In addition, the patient's chronic illness may limit the control individuals feel over social interactions, such as when and where these may occur [38]. For example, Sexton and Munro [39] reported that $30.4 \%$ of their sample of wives of COPD patients were no longer en- gaged in social activities because of the patients' illnesses. Haley and colleagues [40] found no differences in size of social support network or number of contacts with family between caregivers and controls. However, caregivers were significantly less satisfied with their social support than controls and had decreased activities with friends, fewer vacations, and lower church attendance. Data from the present study supports previous work that found higher levels of social support related to better mood [8,13], and adds to the literature by suggesting the relation partially mediates role strains and well-being.

Higher use of emotion-focused coping was associated with lower mood. Lazarus and Folkman [19] suggest that sometimes the use of emotion-focused coping prevents the individual from searching for solutions to a solvable problem, and therefore becomes a counterproductive strategy. Emotion-focused coping styles have been associated with poorer outcome in the general stress and coping literature [41] as well as in the patient literature [20,42], and specifically when examining husbands of patients $[43,44]$. In our 

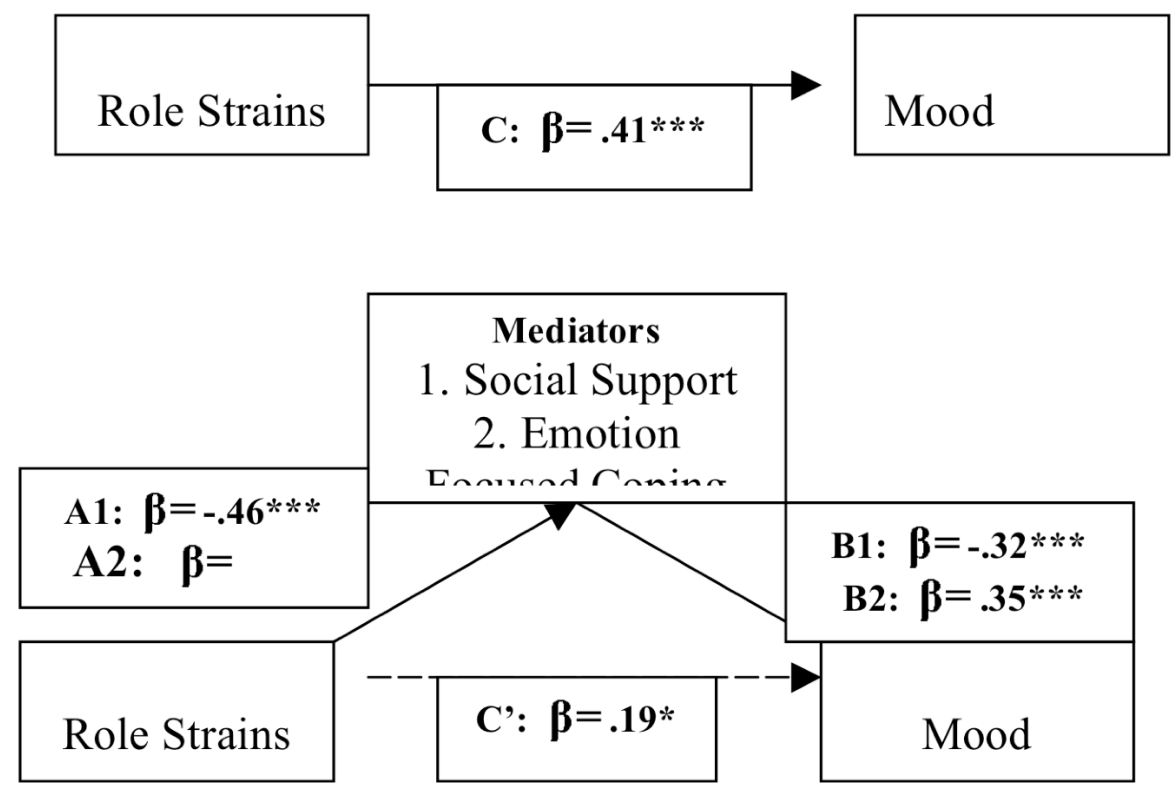

Fig. (2). Model of Mediation for Social Support and Emotion Focused Coping when controlling for income in all regressions. Dotted line illustrates the relation between role strains and mood when the mediators are controlled. $* \mathrm{p}<.05$, two-tailed, $* * \mathrm{p}<.01$, two-tailed, $* * * \mathrm{p}<$ .001 , two-tailed.

sample, problem-focused coping only correlated mildly with social support and education, but not with role strains or mood, as was expected. Because of the varied nature of coping in caregivers, more research is needed to delineate the functions of emotion and problem focused coping within the Stress Process Model.

Our study supports the Stress Process Model in that resources mediated the relation between stressors and psychological outcomes. In addition, our research adds to the literature by replicating findings from Patterson et al. [20] and Goode et al. [21] on the effectiveness of the Stress Process Model to account for the complex nature of the effects of caregiving. Furthermore, the present study provides information regarding the experience of male caregivers. Male caregivers may react differently than female caregivers and so careful attention should be paid to their experiences.

However, the Stress Process Model was not fully supported by our data, as there was no evidence of moderation of resources. Researchers have terms these two options the stress-buffering hypothesis, moderation, which suggests that resources are only, or especially, useful in cases of stress; and the direct effect hypothesis, or mediation, which suggests that resources are always useful, including in cases of stress. Our findings clearly support the latter. There are several possible explanations for these findings. It is possible that in the case of husbands of patients who have been dealing with symptoms for a significant time (average of 8 years since diagnosis), the stress has become chronic. Although Pearlin [15] was focused on long-term stress in his own description of their Stress Process Model, moderation may be more evident in cases of acute stressors, those that have not become part of the everyday life of the individual. Moderation may also show up when comparing groups of individuals with and without stress, where the resources predict outcome in those who are experiencing the stressor, but not in those who are not. Given the paucity of research in this specific population, more work examining the model is necessary to better understand factors associated with moderation and mediation.

Also noteworthy is that problem-focused coping did not play a role in the relationship between stress and outcome in these husbands. The relation between problem-focused coping and the various measures of burden was practically nonexistent when examined through correlation analyses, although the relation between mood and this type of coping was similar to that of mood and emotion-focused coping. There is a large body of research that supports the relation between use of more problem-focused coping and better mood [44]. However, the fact that burden did not relate to problem-focused coping was unexpected. It is also noteworthy that the mean for this type of coping was much smaller than the mean for emotion-focused coping, although the ranges were similar. Clearly, there is much less problemfocused coping happening in these husbands. Although those who feel burdened could use problem-solving strategies to reduce its impact on mood, it seems few enough do to establish a clear link. Possibly, the chronic nature of the burden has exhausted all the avenues for problem solving available. More research into this unexpected finding could clarify the role of each type of coping in the relation between burden and mood.

Our findings suggest that husbands with higher role strains also tend to have poorer social support and use emotion-focused coping strategies that may partially explain the harmful effects of role strains on mood. These findings suggest potential interventions that may impact husbands during their tenure as informal caregivers of their ill spouses. Although there are no published intervention studies for caregivers of cognitively able, non-terminal patients, some effective interventions are suggested by the present study. Information and education about the illness and effective treatments may reduce the use of emotion-focused coping strategies, as these strategies are typically used when individuals feel they can exert little control over a situation [19]. Social 
support groups may serve as avenues through which these spouses can share their experiences and find others who can understand and empathize with them. Social support group members can also share ideas and tips on how to reduce the strains associated with chronic illness in a spouse.

Other interventions may be suggested by the type of role strains that were reported the most, social and sexual. Social role strain involves loss of leisure time activities with friends and acquaintances. Sexual role strain refers to changes in sexual behavior and satisfaction related to the illness. Given the importance of leisure time to well being [45], and of sexuality to marital satisfaction [46], these strains should concern clinicians. Couple interventions focused on improving sexual relations in the presence of pain, and geared toward highlighting the importance of social activities may help not only the husbands' perceptions of role strain, but also the patients' mental health.

Few studies published to date focus on the effects of chronic illness on husbands of patients, and the existing literature is contradictory. For example, among colon cancer patients, male spouses were less adjusted to the disease than female spouses [47]. In other studies, women caregivers report greater difficulty in psychological adjustment [48] and role strains [10] than male caregivers. The fact that our husbands reported greater role strain than Northouse et al. [10] mixed sample of husband and wife caregivers of colon cancer patients suggests that spousal caregivers of fibromyalgia patients warrant additional examination. In addition, much of the research on male caregivers has been done with breast cancer, which may affect the caregiver much differently than a chronic, non-life threatening condition such as fibromyalgia and many other chronic diseases that affect adults.

\section{LIMITATIONS OF THE STUDY}

More data on role strains for a variety of illnesses is needed in order to compare findings across illnesses. Furthermore, data on the typical role strains of husbands whose wives do not have a history of either chronic or acute illness may be helpful in order to place findings such as ours into perspective. Although our husbands report significant strains in a number of roles, men in general may report similar strains in going about their daily lives.

Another shortcoming may be that we did not assess the importance of each of the roles (e.g. social, vocational) to the husband. Pearlin [49] argues that it is the importance of the role that will determine if, and, or how role strain is felt. For example, the wife's illness may have less of an impact on the husband's social role if socializing with others was not a highly valued role in the husband's life before his wife became ill. However, we may have assessed the importance of role by-proxy through the role's relation to mood. For example, the correlations between different role strains and mood may suggest which roles are more important to the individual because of the strength of these relations. However, our findings cannot be conclusive and merit further inquiry.

A longitudinal study, preferably begun soon after the appearance of symptoms in the patients, would significantly clarify the present findings. Such a study would help determine whether there are changes across time in coping efforts, in perceptions of social support, and in burden. Furthermore, it would help clarify whether there are changes in the rela- tions between these variables. The impact of the chronic nature of the strains cannot be fully understood without examining the interplay of these strains with resources and outcome over a long period of time.

The amount of caregiving provided as a whole is expected to rise. Demographic trends in this country show a dramatic increase in the number of caregiving individuals [50]. Longer life spans, an aging baby boomer population and the rise of chronic illness [51] all result in more chronically ill individuals who need care. It will continue to be especially important to consider the role of the spousal caregiver because spouses may be more susceptible to role strain than other types of caregivers [7] and are the most likely individual to serve in the caregiving role.

\section{REFERENCES}

[1] Scharlach AE, Runkle MC, Midanik LT, Soghikian K. Health conditions and service utilization of adults with elder care responsibilities. J Aging Health 1994; 6(3): 336-52.

[2] Wagner CW, Bigatti SM, Storniolo AM. Quality of life of husbands of women with breast cancer. Psychooncology 2005; 14: 112.

[3] Goode WJ. A theory of role strain. Am Sociol Rev 1960; 25: 48396.

[4] Stone R, Cafferata GL, Sangl J. Caregivers of the frail elderly: a national profile. Gerontologist 1987; 27(5): 616-26.

[5] Kramer BJ, Lambert JD. Caregiving as a life course transition among older husbands: A prospective study. Gerontologist 1999; 39(6): 658-67.

[6] Ferguson K, Figley B. Sexuality and rheumatic disease: A prospective study. Sex Disabil 1979; 2: 130-8.

[7] Cantor MH. Strain among caregivers: A study of experience in the United States. Gerontologist 1983; 23(6): 597-604.

[8] Wilson PA, Moore ST, Rubin DS, Bartels PK. Informal caregivers of the chronically ill and their social support: A pilot study. J Gerontol Soc Work 1990;15:155-70.

[9] Northouse LL, Templin T, Mood D. Couples' adjustment to breast disease during the first year following diagnosis. J Behav Med 2001; 24(2): 115-36.

[10] Northouse L, Mood D, Templin T, Mellon S, George T. Couples' patterns of adjustment to colon cancer. Soc Sci Med 2000 2000; 50: 271-84.

[11] Diwan S, Hougham GW, Sachs GA. Strain experienced by caregivers of dementia patients receiving palliative care: findings from the Palliative Excellence in Alzheimer Care Efforts (PEACE) Program. J Palliat Med 2004; 7(6): 797-807.

[12] Blake H, Lincoln NB. Factors associated with strain in co-resident spouses of patients following stroke. Clin Rehabil 2000; 14(3): 307-14.

[13] Chang BL, Brecht ML, Carter PA. Predictors of social support and caregiver outcomes. Women Health 2001; 33(1-2): 39-61.

[14] Edwards AB, Zarit SH, Stephens MAP, Townsend A. Employed family caregivers of cognitively impaired elderly: An examination of role strain and depressive symptoms. Aging Ment Health 2002; 6(1): 55-61.

[15] Pearlin L. Chapter 1: Some conceptual perspectives on the origins and prevention of social stress. 1995 [Retrieved October 14, 2007 from http://www.mhsip.org/nimhdoc/Icombined.pdf ].

[16] Lee JS, Koeske GF, Sales E. Social support buffering of acculturative stress: a study of mental health symptoms among Korean international students. Int J Intercult Relat 2004; 28(5): 399-414.

[17] Ergh TC, Hanks RA, Rapport LJ, Coleman RD. Social support moderates caregiver life satisfaction following traumatic brain injury. J Clin Exp Neuropsychol 2003; 25(8): 1090-101.

[18] Ptacek JT, Pierce GR, Dodge KL, Ptacek JJ. Social support in spouses of cancer patients: What do they get and to what end? Pers Relatsh 1997; 4: 431-49.

[19] Lazarus RS, Folkman S. Stress, Appraisal, and Coping. New York: Springer 1984.

[20] Patterson TL, Semple SJ, Shaw WS, et al. The cultural context of caregiving: a comparison of Alzheimer's caregivers in Shanghai, 
China and San Diego, California. Psychol Med 1998; 28(5): 107184.

[21] Goode KT, Haley WE, Roth DL, Ford GR. Predicting longitudinal changes in caregiver physical and mental health: a stress process model. Health Psychol 1998; 17(2): 190-8.

[22] McCain GA, Scudds RA. The concept of primary fibromyalgia (fibrositis): clinical value, relation and significance to other chronic musculoskeletal pain syndromes. Pain 1988; 33(3): 273-87.

[23] Nicassio PM, Moxham EG, Schuman CE, Gevirtz RN. The contribution of pain, reported sleep quality, and depressive symptoms to fatigue in fibromyalgia. Pain 2002; 100(3): 271-9.

[24] Bigatti SM, Cronan TA. An examination of the physical health, health care use and psychological well-being of spouses of people with fibromyalgia syndrome. Health Psychol 2002; 21(2): 157-66.

[25] Cronan TA, Bigatti SM. Chronic illness: psychological and physical characteristics of women with osteoarthritis and fibromyalgia. Psych Sc 2003; 45(Supp1 II): 63-74.

[26] Sexton DL. Wives of COPD patients. Cast in the role of caretaker. Conn Med 1984; 48(1): 37-40.

[27] Derogatis LR, Derogatis MF. Psychological adjustment to illness administration, scoring, and procedures manual II. Towson, MD: Clin Psychometric Res, Inc. 1990.

[28] Cohen S, Mermelstein R, Kamarck T, Hoberman HM. Measuring the functional components of social support. In: Sarason IG, Sarason BR, Eds. Social Support: Theory, Research, and Applications. The Hague: Nijhoff 1985; p. 73-94.

[29] Folkman S, Lazarus RS. Manual for the Ways of Coping Questionnaire: Consulting Psychol Press 1988.

[30] White NE, Richter JM, Fry C. Coping, social support, and adaptation to chronic illness. West J Nurs Res 1992; 14(2): 211-24.

[31] McNair DM, Lorr M, Droppleman LF. Manual of Profile of Mood States: San Diego 1992.

[32] Frazier PA, Tix AP, Barron KE. Testing moderator and mediator effects in counseling psychology research. J Couns Psychol 2004; 51: 115-34.

[33] Baron RM, Kenny DA. The moderator-mediator variable distinction in social psychological research: Conceptual, strategic, and statistical considerations. J Pers Soc Psychol 1986; 51(6): 1173-82.

[34] Neumann L, Buskila D. Epidemiology of fibromyalgia. Curr Pain Headache Rep 2003; 7(5): 362-8.

[35] Wolfe F, Ross K, Anderson J, Russell IJ, Hebert L. The prevalence and characteristics of fibromyalgia in the general population. Arthritis Rheum1995; 38(1):19-28.

[36] Weir PT, Harlan GA, Nkoy FL, et al. The incidence of fibromyalgia and its associated comorbidities: a population-based retrospec- tive cohort study based on International Classification of Diseases, 9th Revision codes. JCR: J Clin Rheumatol 2006; 12(3): 124-8.

[37] Soederberg S, Lundman B. Transitions experiences by women with fibromyalgia. Health Care Women Int 2001; 22(7): 617-31.

[38] Newsom JT, Schulz R. Social support as a mediator in the relation between functional status and quality of life in older adults. Psychol Aging 1996; 11(1): 34-44.

[39] Sexton DL, Munro BH. Impact of a husband's chronic illness (COPD) on the spouse's life. Res Nurs Health 1985; 8(1): 83-90.

[40] Haley WE, Levine EG, Brown SL, et al. Psychological, social, and health consequences of caring for a relative with senile dementia. J Am Geriatr Soc 1987; 35(5): 405-11.

[41] Berghius JP, Stanton AL. Adjustment to a dyadic stressor: A longitudinal study of coping and depressive symptoms in infertile couples over an insemination attempt. J Consult Clin Psychol 2002; 70(2): 433-8

[42] Jacobsen PB, Sadler IJ, Booth-Jones M, Soety E, Weitzner MA, Fields KK. Predictors of posttraumatic stress disorder symptomology following bone marrow transplantation for cancer. J Consult Clin Psychol 2002; 70(1): 235-40.

[43] Morse SR, Fife B. Coping with a partner's cancer: Adjustment at four stages of the illness trajectory. Oncol Nurs Forum 1998; 25(4): 751-60.

[44] Ptacek J, Smith R, Dodge K. Gender differences in coping with stress: When stressor and appraisals do not differ. Pers Soc Psychol Bull 1994; 20: 421-30.

[45] Cassidy, T. All work and no play: A focus on leisure time as a means for promoting health. Couns Psych Quart 1996; 9(1): 77-90

[46] Butzer B, Campbell L. Adult attachment, sexual satisfaction, and relationship satisfaction: A study of married couples. Pers Rels 2008; 15(1): 141-54

[47] Baider L, Perez T, De-Nour AK. Gender and adjustment to chronic disease: A study of couples with colon cancer. Gen Hosp Psychiatry 1989; 11(1): 1-8.

[48] Hirst M. Carer distress: A prospective, population-based study. Soc Sci Med 2005; 61: 697-708.

[49] Pearlin LI. Role strains and personal stress. In: Kaplan HB, Ed. Psychosocial stress: Trends in theory and research. Orlando: Academic Press Inc. 1983; p. 3-32.

[50] Wagner DL. Comparative analyasis of caregiver data for caregivers to the elderly 1987 and 1997. 1997 [May 20, 2004]; Available from: http://www.caregiving.org/nacanalysis.pdf.

[51] Hoffman C, Rice D, Sung HY. Persons with chronic conditions. Their prevalence and costs. JAMA 1996; 276(18): 1473-9.

This is an open access article licensed under the terms of the Creative Commons Attribution Non-Commercial License (http://creativecommons.org/licenses/by$\mathrm{nc} / 3.0 /$ ) which permits unrestricted, non-commercial use, distribution and reproduction in any medium, provided the work is properly cited. 